Vol. 70, N. ${ }^{\circ}$ III (mayo 20I8), 25-46

\title{
LA CRISIS DE LOS 70 Y LA RECONVERSIÓN INDUSTRIAL EN ESPAÑA COMO PARADIGMA DE CRISIS DE SOBREPRODUCCIÓN CAPITALISTA
}

\author{
LUIS BENÍTEZ MORENO \\ Universidad Complutense de Madrid \\ Recepción de manuscrito: 18 de enero de 2018 \\ Aceptación versión final: 13 abril de 2018
}

\begin{abstract}
RESUMEN Éste es un estudio histórico-estructural acerca de los determinantes de los cambios en la economía española durante la crisis de los años setenta y ochenta. Se trata de identificar las particularidades que en el caso español influyeron en la forma en que se llevó a cabo la reconfiguración de las bases económicas que posibilitaran restaurar la acumulación. El enfoque analítico de la ley del valor permite dilucidar a qué constricciones se enfrentan los capitalistas, así como el papel del Estado, en una economía mundial donde la ley del valor opera a escala mundial con cada vez menos obstáculos.

PALABRAS CLAVE España, ley del valor, crisis de sobreproducción, internacionalización de la eonomía, reconversión industrial.
\end{abstract}

\begin{abstract}
This article offers a historical-structural approach to the determinants of the changes in the Spanish economy during the 1970-1980s' crisis. It aims to identify the particularities that influenced the way the industrial restructuring process was carried in the Spanish case. The labor theory of value analytical approach enables us to elucidate the strictures that capitalists face to survive in a world economy where the law of value operates with ever fewer obstacles. Within the process of markets internationalization, the mode of state intervention in the economy changes substantially.

KEYWORDS Spain, labor theory of value, over-production crisis, internationalization of the economy, industrial restructuring.

Jel COdes F43, N14, O25, P16.
\end{abstract}

\section{INTRODUCCIÓN}

Este artículo tiene como objeto colaborar en una mejor comprensión de los determinantes de los cambios en la estructura económica española durante la crisis contemporánea con el proceso político de la Transición. Se centra en la industria por tratarse del sector paradigmático en que se desarrolla el trabajo productivo. El periodo de estudio abarca cerca de dos décadas, desde finales de los sesenta a finales de los ochenta. Se contempla el enfoque marxista como el más fecundo para analizar las especificidades de la estructura de acumulación en España en relación con las leyes generales de acumulación capitalista, así como para valorar la motivación y alcance de las medidas de política económica implementadas durante el periodo. 
Para proceder con este objetivo es necesario identificar y caracterizar los siguientes elementos, que ejercen como constricciones sobre el cambio estructural y determinan los resultados del proceso de ajuste: la cuestión distributiva, vinculada con la lucha de clases; la dimensión técnica, referida a la tecnología de producción; la competencia entre capitales, que adquiere una nueva entidad con la incorporación de la economía española a la internacionalización de los mercados; y la esfera político-institucional, en el sentido de las posibilidades de intervención estatal. Se considera que el cambio en las formas de intervención estatal resultó decisivo en la reconfiguración de las bases de extracción de plusvalía durante el periodo de crisis.

Sobre este periodo de reestructuración de las bases de la economía española se han planteado tres hipótesis. Que durante los años de la Transición se alcanzó lo que en la literatura marxista se conoce como límite máximo salarial o salario máximo. Que hubo una ausencia de medidas encaminadas a restaurar la tasa de beneficio hasta los gobiernos posteriores a 1982, lo que provocó una mayor intensidad del ajuste. Por último, que el proceso de internacionalización de la economía española careció de dirección estratégica durante todos los periodos de gobierno abarcados en este estudio. Concretamente, la reconversión industrial no se planteó para adaptar los sectores productivos al escenario de la integración en la Comunidad Económica Europea (CEE) y la competencia en los mercados internacionales.

En el siguiente apartado se presenta el marco teórico. Acto seguido se realiza una periodización atendiendo a la evolución de las variables propias del análisis marxista durante la etapa que nos ocupa. Después se estudia el proceso de extraversión de la economía española partiendo de las particularidades heredadas del desarrollismo franquista. Seguidamente se analiza el papel del Estado en el aseguramiento de unas bases que hagan posible la acumulación capitalista en España, con especial atención a las políticas de reconversión industrial de los ochenta. En estas dos últimas secciones se da cuenta de las especificidades que para esta economía presentaba la estructura de acumulación al comienzo de la crisis, así como de las que se desprenden del curso que toma la gestión de la misma. Se finaliza con el apartado de conclusiones, en el que se apuntan posibles líneas de investigación conectadas con el objeto de estudio que aquí se aborda.

\section{MARCO TEÓRICO}

El objetivo de este artículo no es demostrar la validez de la teoría del valor-trabajo (TVT) ni la aplicabilidad de la ley de la caída tendencial de la tasa de ganancia para la economía española. No obstante, es preciso formular ambas concisamente, pues se les hará referencia posteriormente con ocasión del análisis tanto de los determinantes de la crisis de acumulación como de la estrategia de política económica dirigida a su restauración. También resulta oportuno consignar, siquiera mínimamente, la manera en que se interrelacionan las variables centrales al proceso de acumulación cuando peligra su reproducción.

LEY DEL VALOR

La ley del valor es el mecanismo regulador de la economía capitalista (Arrizabalo, 2014). Sea el esquema clásico de reproducción capitalista D-M-P-M'-D', en el que el empresario adelanta una 
masa monetaria (D) con la que adquiere los insumos necesarios (M) para la fabricación de la mercancía final (M'). Entre medio tiene lugar el proceso de producción (P), que da como resultado M', mercancía con un valor superior a M equivalente a D' > D. En el seno de P se desarrolla la jornada laboral, durante la que los trabajadores operan los medios de producción y que se divide en dos partes: una se corresponde con el tiempo de trabajo necesario para reproducir la fuerza de trabajo y otra, con el tiempo de trabajo destinado a la producción del excedente. Así, siendo la jornada laboral v + pv, una porción se dedica a la remuneración de los trabajadores, el salario, que se corresponde tendencialmente con el valor de la fuerza de trabajo v, es decir, el coste de reproducción de la clase obrera en condiciones que permitan su máxima productividad. Este coste se define socialmente, no individualmente, del mismo modo que el tiempo de trabajo necesario para la creación de nuevo valor y que denominamos tiempo de trabajo socialmente necesario, con unas características técnicas y sociales determinadas. La otra porción de trabajo es el plustrabajo, que genera el plusvalor (pv) del que se adueña el capitalista.

La generación de la masa acrecentada de valores que tiene por objeto el proceso de producción se realiza mediante el consumo productivo de los medios de producción y la fuerza de trabajo. De ambos elementos, solo este último tiene la capacidad de crear valor, por lo que recibe el nombre de capital variable (v), en contraposición al capital constante (c), los medios de producción, que trasladan su valor en el proceso productivo, pero no hacen variar el valor de la mercancía. Que solo el trabajo vivo sea capaz de producir un aumento de valor en el proceso productivo es una premisa lógica: «los medios de producción no pueden llevar a cabo por sí solos un proceso productivo completo» (Arrizabalo, 2014, p. 114). La diferencia de valor entre la mercancía inicial m y la que se obtiene al final, M', o, lo que es lo mismo, el incremento de valor se corresponde con la plusvalía, base de la ganancia, que tiene origen en la explotación de la fuerza de trabajo, es decir, en su mercantilización.

Hasta aquí podemos extraer dos implicaciones importantes que expresan la capacidad de la TVL para explicar la formación de precios, tanto de la mano de obra como de las mercancías y para conectar la esfera de producción y de circulación. El precio de una mercancía refleja las condiciones de producción, pues está determinado por su valor, o sea el tiempo de trabajo socialmente necesario para su producción. Aun dependiendo de las condiciones específicas de intercambio, que puede hacer desplazar los precios al alza o a la baja, éstos tienen unos límites emanados de los intereses contrapuestos que concurren en la compraventa. Del mismo modo, el salario, como precio del trabajo, tiende a corresponderse con el valor de la fuerza de trabajo, pero la expresión concreta de aquel depende de la correlación de fuerzas en la negociación entre empresarios y trabajadores.

\section{LEY DE LA CAÍDA TENDENCIAL DE LA TASA DE GANANCIA}

Del desarrollo teórico de la ley del valor se desprende una consecuencia de hondo calado para la acumulación capitalista, como es la tendencia a la caída de la tasa de ganancia. Habida cuenta del lugar central que ocupa la rentabilidad en la conformación de las expectativas empresariales y, por tanto, en la inversión a largo plazo, interesa conocer qué fuerzas la impelen al alza y a la baja, además de las consecuencias de este funcionamiento para el desarrollo de la acumulación. Si la ganancia es la diferencia entre el valor obtenido con la producción y el que 
se disponía al inicio, entonces $\mathrm{D}^{\prime}-\mathrm{D}=(\mathrm{c}+\mathrm{v}+\mathrm{pv})-(\mathrm{c}+\mathrm{v})=\mathrm{pv}$. Por tanto, la tasa de ganancia es $\left(\mathrm{D}^{\prime}-\mathrm{D}\right) / \mathrm{D}=\mathrm{pv} /(\mathrm{c}+\mathrm{v})$. Como la tasa de plusvalía $(\mathrm{pv}$ ) es la relación entre la plusvalía y el capital que crea valor, pv/v, o sea la tasa de explotación, entonces tenemos que g'=pv'/(q+1), donde $\mathrm{q}=\mathrm{c} / \mathrm{v}$ es la composición orgánica del capital. Así, pues, la tasa de ganancia aumenta o disminuye en relación directa con la tasa de plusvalía y en relación inversa con la composición del capital. Dicho de otra forma, la rentabilidad es más elevada cuanto mayor sea el valor creado en relación con el valor de la fuerza de trabajo y cuanto menor sea la proporción de capital que no crea valor respecto al que sí lo crea.

Las implicaciones de lo explicado hasta ahora se completan con una visión dinámica. Ésta se obtiene con la introducción en el análisis de la decisión que toma el capitalista sobre el destino de la plusvalía, que puede ser en todo o en parte consumo productivo o improductivo. La acumulación consiste precisamente en la capitalización de parte del excedente en forma de nuevas inversiones que hagan aumentar el capital productivo. Además de la cuestión de la magnitud de la inversión, esta se concreta en una determinada proporción de capital variable y capital constante susceptible de alterar la composición de capital. Ésta es una decisión que se toma en virtud de las presiones que operan fruto de la competencia entre los distintos capitales. En efecto, la concurrencia de diversos capitalistas en un mercado rentable espolea la competencia por acaparar la mayor cuota posible, en el caso de los más competitivos, o por su supervivencia misma, lo que se consigue en uno u otro caso mediante una bajada de precios. Esto es posible si aumenta la productividad, lo que se traduce en una reducción del coste unitario o, en términos globales, del valor del producto. He aquí el punto en que radica la clave de la cuestión y que permite predicar el carácter contradictorio de la acumulación capitalista. El impulso individual de los capitalistas por llegar como mínimo a la rentabilidad promedio supone el cercenamiento de las bases de la rentabilidad del capital en su conjunto.

El objeto de la cada fracción de capital es su valorización. Como el espacio en que puede realizarse no es ilimitado, los capitalistas tienen intereses enfrentados, lo que se expresa en la competencia entre los diversos capitales. La manera en que opera esta competencia es la búsqueda de una mayor productividad, y esto se consigue a través de una mayor mecanización del trabajo, que permite elevar la cuantía de valor creada por unidad de trabajo. Ello se expresa en el aumento de pv', al incrementarse el numerador en pv/v. No obstante, este movimiento modifica la composición de capital, q, en el proceso productivo, al aumentar la relación c/v. Quiere decir que la proporción empleada del capital que crea valor respecto al que no lo crea se reduce. Esto tiene todo el sentido desde el punto de vista del capital individual si el aumento de plusvalía generado es superior al coste de la nueva inversión, por lo que, si en el cociente pv'/q+1 aumenta el numerador más que el denominador, la tasa de ganancia crece. Ahora bien, esta mayor creación de valor que permite al capitalista vender por encima aún de su coste, pero por debajo del valor de la mercancía, establecido socialmente, no dura para siempre. La capacidad de aprovechamiento de esta plusvalía extraordinaria cesa en cuanto la nueva tecnología de producción se generaliza, merced a los aumentos de productividad que provoca el aumento de la composición del capital de los demás capitalistas, a lo que se ven obligados para no verse expulsados del mercado por la caída de su rentabilidad (Astarita, 2006). Este movimiento termina por agotar la plusvalía extraordinaria, por lo que la tasa de plusvalía retrocede. 
Sin embargo, ahora tenemos una mayor cantidad de capital constante, así que, ceteris paribus, g' disminuye al aumentar el denominador de pv'/q+1. Esto es lo que Marx formula en el Libro III de El capital como ley de la caída tendencial de la tasa de ganancia.

Lo que se ha enunciado se puede formular como ley al ser inherente al proceso de producción capitalista; es decir, es producto del normal desarrollo de la acumulación capitalista. No se trata de una previsión que haya de manifestarse para todo momento y espacio, pues es una tendencia. No se dice que la tasa de ganancia siempre descienda. Efectivamente, sucede que en ocasiones evoluciona al alza, pero esto se debe a la influencia de factores contrarrestantes. Las contratendencias, pues, existen y es preciso tenerlas presentes en el análisis para una mejor comprensión del alcance y fundamento de los movimientos de la tasa de beneficio y, por tanto, del desarrollo de la acumulación. Podemos sistematizar las contratendencias distinguiendo las que inciden en el numerador y en el denominador.

Las primeras consisten en la elevación de la tasa de explotación, bien mediante el recurso al aumento de la jornada laboral o la reducción del salario — plusvalía absoluta—, bien recurriendo a una reducción del tiempo de la jornada laboral dedicado a la reproducción de la fuerza de trabajo y el consiguiente incremento relativo del tiempo dedicado a la producción del plusvalor - plusvalía relativa-, como consecuencia del incremento de la productividad por encima del crecimiento del salario real. La segunda vía debe incidir en la disminución del coste de capital, lo que se traduce en un abaratamiento del capital constante. Existen otros recursos al alcance del capitalista, como la penetración en nuevos mercados o el comercio exterior. Todos ellos son, sin embargo, limitados. El aumento de la composición del capital es inexorable y produce que en el proceso de producción participe una proporción cada vez menor del capital vivo, la fuerza de trabajo, el único del que se extrae la plusvalía. Así, las dificultades crecientes de valorización tienen su fundamento en el aumento de la productividad, pues es cada vez más difícil que pueda darse un aumento de la tasa de plusvalía que compense el efecto negativo sobre la tasa de ganancia del aumento del capital constante, que no crea valor. Cuanto menor es el peso relativo del trabajo vivo y mayor es la proporción dedicada al plustrabajo, más difícil es que los sucesivos incrementos de productividad puedan seguir traduciéndose en subidas suficientes de la tasa de plusvalía.

\section{LAS CRISIS EN EL CAPITALISMO}

Estamos ante una crisis cuando se interrumpe el proceso de acumulación; es decir, cuando deja de aumentar el capital productivo. En circunstancias normales, tiene lugar cuando la rentabilidad cae por debajo de un umbral que hace inviable mantener la reproducción ampliada del capital. Este fenómeno se produce precisamente por la sobreacumulación de capital, consecuencia del normal desarrollo del capitalismo y que se plasma en una sobreproducción de mercancías. Se abre entonces una crisis de realización, pues el capitalista es incapaz de realizar el valor contenido en sus mercancías y, por tanto, no solo no obtiene la plusvalía sino que pierde todo el valor depositado en ellas. Las crisis ponen de manifiesto la existencia de un exceso de capacidad productiva respecto de las posibilidades de valorización del capital. Se producen cuando el curso de la acumulación agota los espacios de extracción de plusvalía. Es perentorio, llegado ese caso, restaurar la rentabilidad, lo que se ha acometido históricamente de 
dos maneras: mediante la destrucción de capital y mediante la desvalorización de la fuerza de trabajo. El recurso a la primera vía como forma de abrir nuevos espacios duraderos de rentabilidad, tradicionalmente a través de la destrucción bélica, ha tenido su papel histórico pero no se compadece con la situación de crisis que se analiza en el periodo de estudio.

Durante los años cincuenta y sesenta del pasado siglo, en los países del centro capitalista tuvo lugar un aumento continuado de los salarios reales posibilitado por las fuertes ganancias de productividad. Como el salario es fuente de demanda, su importante avance favoreció la expansión de la producción. No obstante, a finales de los sesenta se vislumbraba una fase de estancamiento. La fortaleza de las organizaciones obreras salvaguardó sus condiciones de trabajo, impidiendo un alza en la tasa de explotación a pesar de la imparable automatización de los procesos de producción. Esta dinámica unida a la progresiva diseminación de las modernas técnicas productivas afectó a la rentabilidad (Albarracín, 1991). El oscurecimiento de las expectativas de beneficio se terminó plasmando en acusados recortes en los planes de inversión que condujeron a la depresión económica. En primera instancia se produjo una reducción en el uso de la capacidad instalada en las industrias de bienes de equipo. El contagio a las industrias de bienes de consumo, a causa del descenso en sus ventas por el aumento del desempleo, no se hizo esperar (Catalán, 1991).

Como el salario es, antes que factor de demanda, la porción del valor creado que se contrapone a la plusvalía, la disminución de su carga debe ser la respuesta más inmediata del capitalista para restaurar la tasa de ganancia. Se ve reforzado en su capacidad para imponer tal recorte por la situación de bancarrotas y la escalada del desempleo fruto del contexto de crisis. El ejército industrial de reserva ejerce una presión a la baja en los salarios siempre funcional a la acumulación, pero que es fundamental cuando éstos se aproximan al límite superior salarial o salario máximo, incompatibles con la extracción de la plusvalía suficiente.

Una vez expuesto este breve resumen de los principales elementos del análisis económico marxista, puede pasarse al estudio de los cambios en la estructura industrial española como consecuencia de la crisis de acumulación que atravesó la economía desde 1975 hasta bien entrados los años ochenta. Se trata de determinar en qué medida el fenómeno objeto de estudio puede subsumirse en este marco teórico, valorando las especificidades del caso concreto español. La forma en que se aborda dicha tarea es mediante un estudio histórico-estructural, entendiendo como tal:

[...] El que, por un lado, considera en su totalidad las «condiciones históricas particulares» económicas y sociales - tanto en el plano nacional como en el plano externo de una formación social y, por otro, comprende, «en las situaciones estructurales dadas, los objetivos e intereses que dan sentido, orientan o alientan el conflicto entre grupos y clases y los movimientos sociales que “ponen en marcha” las sociedades». (Cardoso y Faletto, 1969, p. 17) [Citado en Braña, 1981, p. 17]

\section{PERIODIZACIÓN}

En este apartado se muestra una división del periodo de estudio atendiendo a la evolución de la tasa de beneficio, de acuerdo con las estimaciones de los trabajos de Cámara (2005) y Echebarria y Herrero (1989). También se ofrece una distinción según el comportamiento de 
la participación del excedente bruto de explotación (EBE) en la producción, variable empleada en el análisis de Navinés (1989). El punto de inflexión en la evolución de la variable empleada por Navinés se produce en 1977. Hasta ese año, la relación EBE/PIB (producto interno bruto) decrece, pasando a elevarse a partir de entonces. El autor traza subperiodos atendiendo también al crecimiento de la producción agregada, por lo que la compartimentación del periodo que estudia queda tal que: i) 1964-1974, ii) 74-77, iii) 77-81, iv) $81-84$ y v) $84-86$.

i) 1964-1974: en estos años se produce un intenso crecimiento económico merced a un notable flujo inversor. El PIB a coste de factores y la formación bruta de capital fijo aumentaron un $6,62 \%$ y un $9,42 \%$, respectivamente, ambos en tasas anuales acumulativas. Por su parte, las rentas salariales elevaron ocho puntos su participación en la renta nacional; la misma magnitud que la pérdida del excedente, que pasó de acaparar un $53 \%$ a un $45 \%$ de la renta. El crecimiento de la productividad habría financiado un $40 \%$ del incremento del coste laboral unitario; la subida de precios, un $55 \%$.

ii) 1974-1977: el EBE se reduce otros tres puntos hasta el $42 \%$ en una etapa de estancamiento de la producción y en la que la FBCF cae un 3,37\% en tasas anuales acumulativas. En cuanto a la evolución del coste laboral, el incremento de productividad solo cubrió el 17\%, dejando a la subida de precios la absorción del $80 \%$ restante.

iii) 1977-1981: la inversión sigue cayendo hasta 1979. El ritmo de producción sigue deteriorándose, lo que sumado a la desaparición de numerosas empresas condujo a un aumento del desempleo desde el 5,67\% hasta el 14,31\%. Junto a este fenómeno se limita el crecimiento del coste laboral, que queda cubierto en un $19 \%$ por la ganancia de productividad y en un $85 \%$ por la subida de precios. El excedente, así, gana cuota por primera vez.

iv) 1981-1984: se inicia una recuperación en el crecimiento de la producción, aunque la inversión en capital fijo decrece levemente. Durante esta etapa los precios crecen más que el coste laboral y el crecimiento de este se desacelera más que el de la productividad — que pasa a cubrir un 32\% del incremento-, por lo que el EBE crece con fuerza, pasando de suponer el $43 \%$ al 49\% del PIB. El paro alcanza el 20,52\%.

v) 1984-1986: el PIB se incrementa ya a buen ritmo, pero la cuota del excedente apenas aumenta. Los precios siguen subiendo más que el coste laboral, pero la productividad crece poco —cubre el $24 \%$ del aumento de aquel- a pesar de que los niveles de inversión superan incluso a aquellos de los años sesenta.

Echebarria y Herrero toman como variable la tasa de beneficio del sector industrial, cociente entre el beneficio neto en la industria y el stock neto de capital acumulado, ambos en pesetas corrientes. Alcanza su punto de inflexión entre los años 1982 y 1983 . Encuentran las siguientes fases: i) 1967-1974, ii) 75-80, iii) 81-85 y iv) 86-88.

i) 1967-1974: en este intervalo la productividad sigue aumentando, pero menos pronunciadamente que hasta entonces $-6,4 \%$, por un $9,6 \%$ durante la primera mitad de los sesenta-. El salario real continúa su crecimiento y lo hacen especialmente las prestaciones sociales a partir de 1967. Se encuentra que el leve ascenso de la tasa de plusvalía no impide la caída de la tasa de beneficio desde el máximo del año anterior, pues la composición orgánica del capital sigue una fuerte progresión al alza. Cabe añadir que la evolución de los precios de los bienes de equipo supera al de los precios del consumo, por lo que los bienes de capital se encarecen relativamente. 
ii) 1975-1980: la tasa de plusvalía se deprime en gran medida, al aumentar aún más intensamente los salarios reales y reducirse el crecimiento de la productividad debido al abrupto retroceso de la inversión y la caída en la utilización de la capacidad instalada. A esto se une que el capital por trabajador crece intensamente merced a la expulsión de una ingente cantidad de mano de obra. Todo ello incide en un continuo deterioro del beneficio industrial.

iii) 1981-1985: la tasa de beneficio industrial toca fondo en los años 1982 y 1983, para recuperarse con intensidad hasta 1985. La exitosa política de contención salarial unida a un nuevo incremento de la productividad a causa de la inversión sustitutiva de mano de obra impulsa al alza la tasa de plusvalía, que compensa con creces el aumento de capital por trabajador.

iv) 1986-1988: el cambio de tendencia en el crecimiento económico que se observa desde el año anterior promueve un importante relanzamiento de la inversión productiva que, no obstante, no se traduce en grandes ganancias de productividad al incorporarse igualmente abundante mano de obra. La tasa de plusvalía retrocede levemente y la tasa de beneficio se estanca.

Por su parte, Cámara analiza el comportamiento de la tasa de beneficio general para la segunda mitad del siglo. Como muestra la figura 1, desde el nivel máximo alcanzado por la tasa de ganancia en 1963, ésta va descendiendo hasta 1979, cuando alcanza un mínimo. La trayectoria remonta hasta 1989, cuando se corta su progresión ascendente.

La figura 2 muestra la trayectoria de la tasa de ganancia junto con sus dos componentes, expresados como tasa de plusvalía y composición de valor del capital (CVC), que es una medida de la composición técnica del capital y el valor relativo del capital respecto a la mano de obra. Para una mayor claridad, se ilustra la inversa de la CVC porque es directamente proporcional a la tasa de ganancia. Así, el descenso de la curva de la inversa de cvc indica un crecimiento de la composición orgánica del capital, lo que se traduce en una presión a la baja sobre la rentabilidad. Aunque existe cierta interdependencia entre la distribución del ingreso y la tecnología de producción, es posible extraer algunas enseñanzas.

Si nos fijamos en la primera parte de nuestro periodo, la que va desde 1963 hasta 1979, comprobamos que tiene lugar una caída pronunciada de la tasa de explotación. De hecho, entre 1960 y 1973 los salarios reales se multiplicaron por 2,3; o lo que es lo mismo, subieron un 6,7\% anual de media. Ello, posibilitado por los fuertes incrementos de productividad que se dieron en esa etapa. En cambio, la composición del capital mantenía al final de esta etapa un nivel similar al del comienzo. Cabe concluir, por tanto, que la caída de la rentabilidad se corresponde con la bajada de la tasa de plusvalía.

Puede apreciarse que en 1973 comienza a darse un aumento muy intenso de la composición de valor del capital. Se produce entonces un empeoramiento más acentuado de la rentabilidad que solo se revierte a partir de 1979 por el gran aumento de la tasa de plusvalía, especialmente intenso entre 1983 y 1986. Debe hacerse notar que, desde la segunda mitad de los setenta, el progresivo abaratamiento del capital en relación con la mano de obra que venía operando en el pasado deja de tener el efecto contrarrestante sobre la composición técnica del capital.

Con lo visto hasta ahora sobre la situación de ruptura y posterior restauración de la acumulación, puede predicarse su encaje en el esquema clásico de crisis, con el añadido de la inflación, producto de la exacerbación del conflicto distributivo en el contexto de un nuevo marco institucional. La desaparición del almirante Carrero Blanco en 1973, presidente del Gobierno 
Figura 1. Evolución de la tasa de ganancia en España (1954-2000)

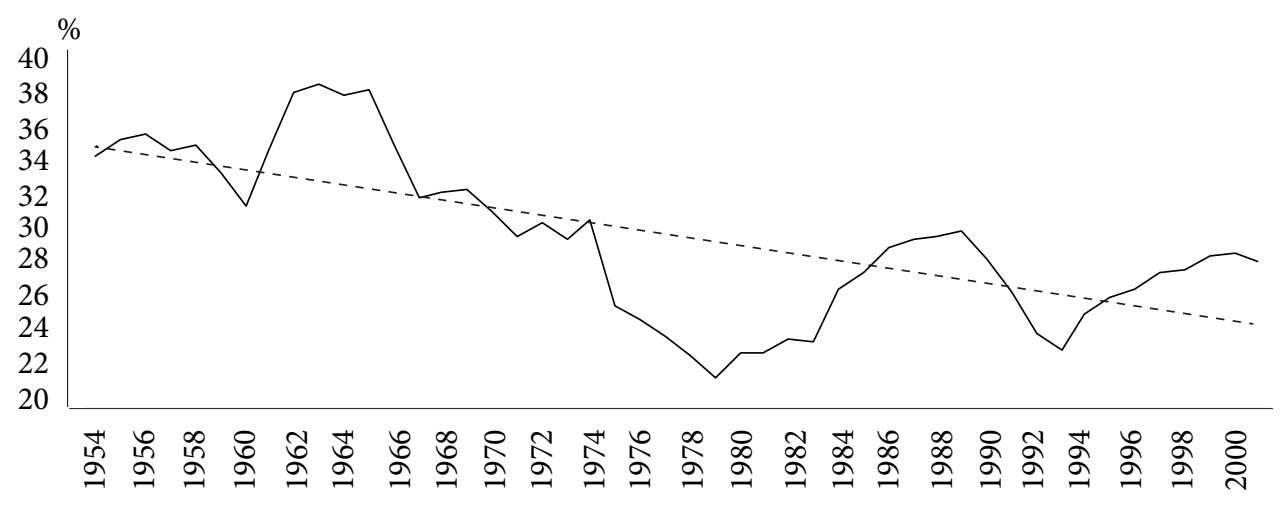

Fuente: Cámara (2005).

Figura 2. Evolución de la tasa de ganancia y sus componentes en España (1954-2000)

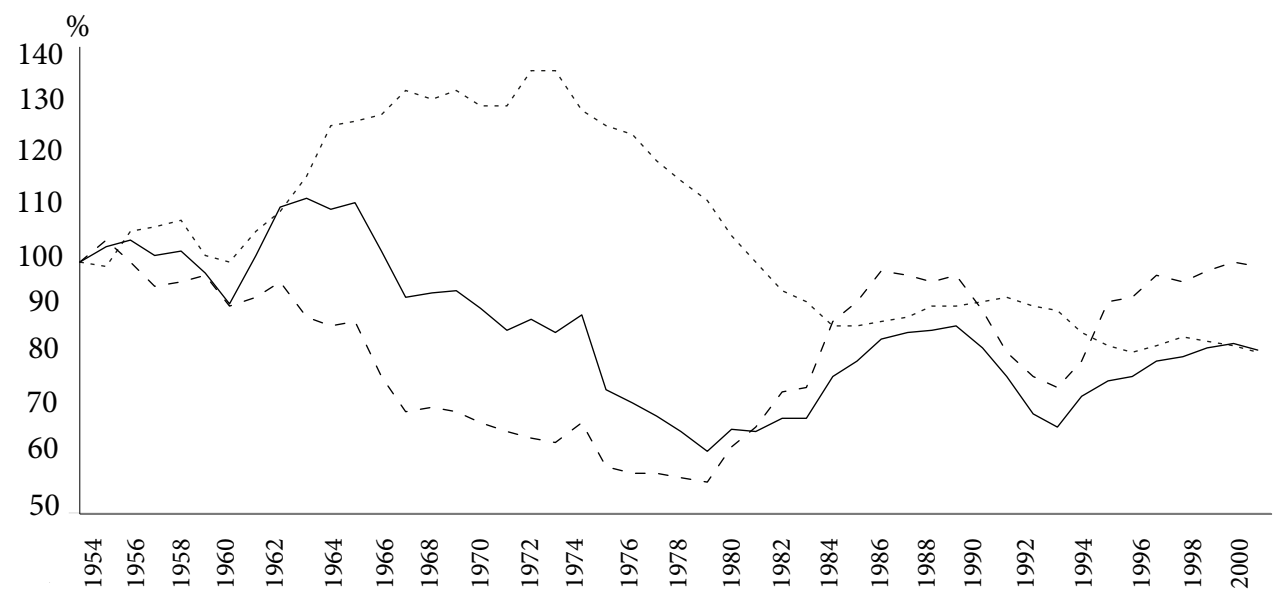

Fuente: Cámara (2005).

y llamado a ocupar la jefatura del Estado, desencadena la indefectible descomposición del régimen franquista, lo que unido al clima de fuerte movilización social coloca a los trabajadores en una posición de fuerza para exigir aumentos salariales. A ello lo acompaña el práctico agotamiento del ejército industrial de reserva. Por lo que respecta a la clase empresarial, desde 1975 tiene lugar lo que se ha denominado «huelga de inversiones», situación que se mantendría durante unos años. Así, la inversión en términos reales se redujo un 4\% en 1977 y un 6,4\% en 
1978. Además, las fracciones del capital con mayor cercanía al poder político, ante el deterioro de sus condiciones de negocio, se apresuraron a reclamar la asistencia por parte del Estado para salvaguardar su supervivencia, lo que suscitó la puesta en marcha de multitud de medidas ad hoc como forma de intervención pública, según veremos en el apartado quinto (González, 1991a). En 1975, la economía entra en recesión en medio de una fase de expansión del sector público con una marcada influencia alcista sobre los costes laborales, pues se financia además de con mayores impuestos sobre el salario con una subida de las cotizaciones sociales. Se alimenta así el círculo vicioso de crecimiento de los salarios y de la inflación, pues los trabajadores no están dispuestos a perder poder adquisitivo ni los empresarios a ceder más plusvalía. La facilidad de los empresarios para trasladar su aumento de costes a los precios provoca que el índice de precios al consumo (IPC) se dispare desde 1974.

A partir de la firma de los Pactos de la Moncloa en 1977, parece que la correlación de fuerzas comienza a cambiar y el discurso de las principales organizaciones obreras se plaga de referencias a la «solidaridad ante la crisis». Los salarios se desaceleran más intensamente que los precios y, desde 1979, crecen por debajo de la productividad; el coste laboral unitario real cae sensiblemente. Estos factores hicieron posible la recuperación parcial de las tasas de beneficio, que con los datos manejados por Albarracín se produce desde 1982. Desde 1977 a 1985, el PIB creció apenas un 1,1\% anual, la ocupación descendió en más de un millón seiscientas mil personas y la productividad avanzó una media anual del 3\%. La remuneración de los asalariados como parte del PIB descendió 5,24 puntos - 3,5 puntos solo entre 1982 y 1985-. Dentro del PIB de los asalariados, el salario pasó de suponer en 1977 el 68,3\% de la producción media por trabajador al 58,7\% en 1989. A partir de 1986, el crecimiento de la productividad se estanca por el notable incremento del empleo en la fase de crecimiento iniciada el año anterior, descendiendo la relación capital/producto. Si hasta 1985 la inversión por trabajador se mantuvo a pesar de la caída de la formación bruta de capital (FBC), debido al efecto composición, a partir de entonces, a pesar de que la inversión crece sensiblemente, la intensidad de capital solo se mantiene, por el efecto de la subida de la fuerza de trabajo y la utilización de la capacidad instalada. En términos reales, en la década anterior a la crisis, de 1964 a 1974, la FBCF creció a una tasa media acumulativa del 8,6\%, llegando a suponer el $28 \%$ del PIB, 4,7 puntos más que en 1964. Por el contrario, en la década siguiente, de 1974 a 1984, siempre en términos reales, la FBCF descendió un 2,4\% anual, hasta llegar al 18,8\% del PIB en ese último año (Albarracín, 1991).

\section{INTERNACIONALIZACIÓN DE LA ECONOMÍA}

Para explicar los condicionantes del proceso de internacionalización de la economía española resulta conveniente examinar las bases sobre las que se afianzó el régimen de acumulación en España durante la fase de expansión anterior a la crisis. Este análisis se conecta con el posterior tratamiento de la política de reconversión.

\section{PARTICULARIDADES DE LA ESTRUCTURA ECONÓMICA HEREDADA DEL FRANQUISMO}

A grandes rasgos, el modelo de desarrollo franquista no se separa de los emprendidos en las economías que habían puesto o estaban poniendo en marcha procesos de industrialización, 
pero es posible encontrar algunos elementos que particularizan el camino por el que discurrió el caso español. Estas particularidades se expresan, más que en diferencias estratégicas, en diferencias de nivel o cuantitativas. Otras se desprenden del marco político-institucional. Por último, cabe añadir decisiones concretas de política económica que se separaron del criterio de intervención seguido en las economías del entorno. La tesis principal que aquí se plantea es que, en buena medida, los factores que impulsaron el crecimiento sin precedentes de la economía durante los años cincuenta y sesenta sembraron las bases de los futuros problemas que se manifestaron con la crisis. Asimismo, el contexto internacional tuvo una influencia decisiva en las posibilidades de implementar con éxito la estrategia desarrollista, al igual que desempeñó un papel determinante en su decadencia (Catalán, 1991).

La destrucción y miseria surgidas de la Guerra Civil se prolongaron durante la posguerra y la autarquía. Baste un dato para ilustrar la magnitud del empeoramiento de las condiciones de vida: los niveles de consumo per cápita de carne en 1936 en una ciudad como Barcelona solo se recuperaron en 1962 (Catalán, 1991, p. 102). Dejado atrás el periodo de autarquía, se inició una intensa fase de crecimiento. Así, entre 1950 y 1974, el PIB per cápita, medido en dólares con paridad de poder adquisitivo, aumentó un 5,2\% anual, por lo que pasó de representar el 43\% del británico al 80\% en ese tiempo. El crecimiento fue tan notable debido al bajísimo nivel de partida y a la alta formación de capital en la industria. Debe añadirse que también se vio favorecido por una serie de circunstancias ajenas a la formación social española, como fueron la disponibilidad suficiente de medios de pago a partir de 1959, los ingresos por remesas de emigrantes y turismo y la afluencia de inversión extranjera.

No obstante el indudable progreso técnico que se dio en esas dos décadas, la industria española mantuvo su «condición periférica dentro del concierto europeo» (Catalán, 1991, p. 105) $\mathrm{o}$ «dependiente, en tanto los elementos fundamentales de la acumulación y la reproducción pasan por el exterior de la formación social española» (Braña, 1981, p. 492). Pueden encontrarse una serie de factores que propiciaron que así fuera o que dificultaron el desarrollo de una industrialización más autocentrada, aunque parece razonable pensar que:

La actuación del Estado no ha puesto en ningún momento medios para alterar o contrarrestar el proceso de especialización productiva, sino que, todo lo contrario, ha incentivado a aquellas ramas y secciones que el proceso de jerarquización productiva ha asignado a la formación social española en el contexto de la división internacional del trabajo. (Braña, 1981, p. 497)

Se ha apuntado también que «los fracasos económicos del Régimen desencadenaron los cambios de rumbo», mientras que «los éxitos tendieron a bloquear las reformas» (Catalán, 1991, pp. 106-107).

En cualquier caso, entre las debilidades de la industria española respecto a las europeas más avanzadas pueden destacarse un mayor grado de dualismo productivo, un menor tamaño medio de las empresas, una menor diversificación exportadora y una productividad más baja. A comienzos de la década de los sesenta, la productividad del trabajo en España no era siquiera la mitad de la media de las economías que integraban la CEE; cuando llegó la crisis todavía era apenas un 60\% (Albarracín, 1991, pp. 318-320). Además, su desarrollo se basó en la adquisición de patentes y licencias foráneas, lo que revela una alta dependencia tecnológica 
fruto de una baja inversión en I+D. No debe escapársenos la peculiar forma en que se desarrolló la acumulación durante los primeros años del Régimen, de una forma muy primitiva, favorecida por las licencias de importación y el contrabando, en unas condiciones de privilegio para la clase empresarial que dificultaron después su capacidad para competir una vez superado el periodo autárquico. Así, buena parte de los negocios más rentables se desarrollaron en actividades que no estimulaban la innovación productiva, señaladamente los sectores turístico, bancario y de la construcción. Como documenta Braña en su tesis doctoral, el criterio primordial a la hora de determinar el apoyo estatal a sectores o empresas fue el de su cercanía al poder político.

Uno de los elementos clave en la conformación de las relaciones económicas durante el franquismo estuvo enraizado en la pauperización de las masas populares tras la Guerra Civil. El marco autoritario de relaciones laborales que se mantuvo posteriormente coadyuvó a mantener el salario real en unos niveles por debajo de su nivel «normal». Como contraparte se encontraban unas tasas de plusvalía anormalmente altas en comparación con las economías centrales; entre un 30\% y un 50\%, por las superiores al 70\% del caso español durante los primeros años cincuenta (Cámara, 2005). Esta sobresaliente extracción de plusvalía absoluta servía para el acaparamiento de grandes masas de capital monetario que, sin embargo, no se traducían en inversiones productivas, sino que se dedicaban a operaciones especulativas - adquisiciones inmobiliarias, de terrenos, de patrimonio, dirigidas al mercado negro-, al consumo suntuario o bien se evadían al exterior. Puede afirmarse que en esta primera etapa «el Estado dispuso de herramientas decisivas para apoyar y ayudar a configurar un proceso de acumulación de carácter básicamente extensivo cuyo soporte principal sería la reducción del poder adquisitivo de la clase obrera y otras capas populares» (Echebarria y Herrero, 1989, p. 14). Ante unos salarios tan deprimidos y un mercado interno muy limitado, los incentivos para la inversión en maquinaria eran reducidos. Por tanto, era difícil que se produjeran aumentos sensibles de productividad que, a su vez, incidieran en un aumento del salario real.

Ha tendido a situarse el programa de estabilización de 1959 como la frontera entre dos políticas económicas de signo radicalmente distinto, pero la realidad dista de ser compatible con esa afirmación. El gobierno entrante en 1951 declaró como objetivo central de su programa económico la industrialización y el aumento de la productividad. Los fondos públicos destinados a la inversión y apoyo a una variedad de ramas aumentaron considerablemente en un contexto internacional que comenzaba a ser mucho más favorable tras la reconstrucción europea y el consiguiente crecimiento económico y desarrollo industrial. Adicionalmente, durante los siguientes años se rompe el aislamiento diplomático del Régimen, que encuentra apoyo financiero y tecnológico de Estados Unidos. De esta manera, la economía española va adquiriendo un papel en la división internacional del trabajo. Durante estos años se destinan más recursos a la inversión productiva y se producen cambios en la organización del trabajo y la regulación laboral que conllevaron un aumento de la productividad, sobre todo en las grandes empresas. Se comenzó a desplegar, entonces, una acumulación intensiva basada en la plusvalía relativa. No obstante, expresión de las contradicciones del proceso de acumulación entre las nuevas fuerzas y los instrumentos y condicionantes aún vigentes, durante este tiempo la crisis de sobreacumulación era una amenaza muy presente por la dificultad del mercado interno para 
absorber las mercancías resultantes de las necesidades de valorización del capital industrial. Producto de los graves desequilibrios y perturbaciones que se manifestaron con todo rigor a partir de 1956 es el Plan de Estabilización de 1959, encaminado a afianzar la línea desarrollista proyectada en los años anteriores (Echebarria y Herrero, 1989).

A pesar de los grandes cambios que tuvieron lugar durante estas décadas, en el sector manufacturero persistían algunos rasgos propios del periodo autárquico, exponentes de los problemas de especialización de la industria española. Tratándose de un país con una escasa dotación energética y de materias primas, su industria estaba especializada precisamente en la producción de bienes intensivos en estos suministros. El sobredimensionamiento de las ramas manufactureras de bienes de consumo intermedio adquiere mayor gravedad si se consideran los fuertes aumentos de capacidad instalada acometidos ya en la década de los setenta, bajo el paraguas de los planes de desarrollo, que preveían un aumento sostenido de la demanda global de estas mercancías. Igualmente destacable es la alta aportación de las industrias más tradicionales en el empleo y el valor añadido, caso de los textiles, el calzado y la madera, muy sensibles a la subida de los costes laborales. Por otra parte, se trataba de mercados muy poco concentrados y con un tamaño de las empresas muy inferior a la media general. El advenimiento de la competencia de otros mercados, señaladamente los Newly Industrialized Country, impactó muy negativamente en el tejido industrial español; no solo en estas ramas más tradicionales, sino también en otras más punteras y en las que la economía española se había demostrado razonablemente competitiva en los años sesenta, como en los bienes de consumo duradero y de equipo, que compartían los rasgos que se han precisado para las más tradicionales (Catalán, 1991).

\section{DEL ACUERDO PREFERENCIAL A LA ADHESIÓN A LA COMUNIDAD ECONÓMICA EUROPEA}

La economía española no fue ajena a la progresiva internacionalización de la economía mundial durante la segunda mitad del siglo xx, aunque se incorporó a dicho proceso con retraso por circunstancias tanto políticas como económicas. En el curso de esta transformación siempre hay fracciones del capital perjudicadas y otras, las más pujantes, con mayor capacidad para aprovechar las nuevas oportunidades de expansión y que, por tanto, pueden verse beneficiadas. La búsqueda de nuevas bases de extracción de plusvalía y nuevos mercados donde realizarla explica el ímpetu expansionista de los capitales, especialmente en un contexto de sobreproducción y saturación de mercados. Desde el punto de vista público, la inserción en la economía mundial conlleva la renuncia a determinadas prerrogativas del Estado como ente regulador de la dinámica económica, bien como resultado de su pérdida de eficacia o a resultas de un compromiso político que implique una cesión de soberanía. Por otra parte, puede ocurrir que las decisiones clave sobre la acumulación pasen a ser ajenas a la formación social de que se trate, en lo que se da en llamar desestructuración de la economía; así, la producción no se orienta atendiendo a las necesidades internas, sino a las necesidades de valorización del capital transnacional. Se da entonces una «ruptura espacial entre la generación de plusvalía y la movilización del beneficio, lo que impide que se forme una tasa de beneficio media general en los límites de un sistema productivo» (Gómez, 1991, p. 468).

La penetración del capital extranjero en España no supone una novedad de la crisis, pues ya se había erigido como puntal del desarrollismo, especialmente en lo referente a la tecnología. 
Puede afirmarse que es un fenómeno de importancia creciente desde el estallido de la crisis, que propició la venta de numerosas empresas a capitales foráneos, y, más aún, con las expectativas creadas por la integración comunitaria. Existen tres hitos en este proceso de internacionalización de la economía española durante el periodo: el Plan de Estabilización de 1959, el Acuerdo Preferencial de 1970 y la adhesión a la CEE en 1986.

Por lo que respecta al Plan de Estabilización, se trata de un ajuste de tipo clásico impuesto por las perturbaciones macroeconómicas que se habían venido poniendo de manifiesto en los años anteriores y, de forma más inmediata, por el desequilibrio exterior que estaba produciendo la aceleración de la acumulación. Así pues, se estimó que era necesario captar capital extranjero en mayor cuantía para financiar la transformación del tejido productivo, así como impulsar los intercambios comerciales con el exterior mediante una mayor liberalización, aunque la protección arancelaria mantuvo un nivel alto. Por tanto, el propósito del plan era preparar la economía para esta apertura y potenciar los efectos que se pretendían, por ejemplo, con la posibilidad de repatriación de los beneficios obtenidos. El plan dio sus frutos sin deparar efectos perniciosos sobre el equilibrio o la producción nacional (Montes, 1991).

El Acuerdo Preferencial de 1970 con la CEE limitó su alcance al ámbito comercial, con una reducción de aranceles entre las partes y la eliminación de ciertas restricciones en cantidades. Como estas rebajas fueron mayores por parte de los países de la Comunidad, puede decirse que España se vio beneficiada. El resultado fue un aumento considerable de las exportaciones españolas hacia Europa acompañado de una sustitución de importaciones provenientes del resto del mundo por otras procedentes de la CEE, ahora con un menor coste, pues no tuvo como efecto una apertura especialmente significativa del mercado español. En un contexto negativo para el comercio mundial, las exportaciones españolas crecieron de forma sostenida hasta 1984, cuando se alcanzó el menor déficit comercial en relación al PIB en dos décadas.

Las negociaciones para la adhesión a la CEE comenzaron en 1979 y concluyeron en 1985, aunque se intensificaron en los últimos años. Finalmente entró en vigor en 1986 y comportó la supresión de las barreras arancelarias, la adopción del arancel común y la eliminación de los obstáculos a la libre competencia y la formación de precios. En la práctica, supuso deshacerse de la protección exterior a cambio del desarme arancelario de las economías de la CEE, que contaban con unos niveles muy inferiores a los españoles. Si toda negociación se basa en una contraposición de intereses, en este caso la maraña de intereses cruzados era particularmente compleja en tanto que no solo había intereses enfrentados entre países, sino en el interior de la burguesía europea. Más allá de los antagonismos de intereses específicos, se ponía de manifiesto una «contradicción básica»: su interés:

[P]or forzar una unidad económica y política que facilitara el desarrollo y competencia del capitalismo europeo frente a los otros dos bloques imperialistas de EE. UU. y Japón y las ventajas que cada burguesía, con sus complejos sectores internos, obtenía de la existencia de un Estado protector propio para garantizar la rentabilidad y la supervivencia del sistema. (Montes, 1991, p. 253)

Téngase en cuenta que, como consecuencia de la larga crisis económica, los conflictos de interés se habían exacerbado, las economías comunitarias se encontraban inmersas en sus propios procesos de ajuste y la CEE contaba con desequilibrios de importancia en términos de 
desempleo, sobrecapacidad productiva, excedentes agrícolas, presupuestarios, etc. Debe considerarse la posición de fuerza negociadora con que contaba cada parte, mucho más débil en el caso español por varias razones. Cada país miembro contaba con poder de veto; es decir, la incorporación solo se produciría si ningún país consideraba que los términos en que se iba a realizar le resultaban perjudiciales, por lo que la posibilidad de que la economía española obtuviera alguna concesión relevante para sus intereses era remota de partida. La disposición del Gobierno español no hacía más que abundar en esta circunstancia, pues había adquirido un fuerte compromiso político con la integración. Al europeísmo por principio con que se abordó desde el poder político español este proceso se añadían las urgencias políticas, que determinaron las prisas por concluir al acuerdo y la consiguiente precipitación en las negociaciones, en las que la parte española careció por propia iniciativa de bazas con las que ejercer presión para oponerse a los términos que le fueran más perjudiciales.

La cuestión que suscitó más controversia fue la de los productos agrícolas, debido a que la incorporación de España suponía un aumento del 30\% en la producción y del 14\% en el número de consumidores en la CEE. De los acuerdos finalmente surgió una asimetría entre los términos relativos al sector industrial y al sector agrícola. En este último, el más regulado de la CEE, la economía española podía considerarse competitiva, especialmente en varios productos que suponían una amenaza para la producción de otros países. Se introdujeron, a diferencia de para el sector industrial, importantes excepciones de plazo y cláusulas de salvaguardia y el acuerdo resultó muy impreciso. Puede decirse que los intereses agrarios comunitarios quedaron protegidos; no así los españoles, que hubieron de afrontar un ajuste productivo de envergadura. Se llega, por tanto, a una simetría solo formal que perjudicaba claramente los intereses españoles. Prueba de ello es que la CEE adelantó varios años, a 1989, la culminación del resto de etapas del desarme arancelario frente a España, vistos los nefastos resultados que estaba produciendo para los productores españoles (Montes, 1991).

La consecuencia inmediata de la adhesión fue un desmesurado incremento de las importaciones durante 1986 que continuó durante los siguientes años, aunque a un ritmo más moderado. El desequilibrio exterior pasó de suponer en 1985 el 3,3\% del PIB al 7,1\% en 1989. En pesetas constantes de 1980, la diferencia se eleva desde el 1,4\% al 11,2\% del PIB en estos cuatro años. Ello ocurrió en un contexto de fuerte recuperación del crecimiento de la producción desde 1985 y con una drástica apreciación de la peseta en 1986 por la entrada en masa de capitales producto de la integración. Debe hacerse notar que durante los cuatro primeros años transcurridos desde la adhesión el diferencial de crecimiento de la demanda agregada y el PIB fue de 2,7 puntos por año de media, lo que se traducía en una pérdida de producción y empleo potenciales. Se pasó de un superávit por cuenta corriente de USD 4100 millones en 1986 a un déficit de USD 11.00o millones en 1989. Para lograr financiación exterior era vital mantener la estabilidad del tipo de cambio, objetivo al que se supeditó toda la actuación económica desde la integración en el Sistema Monetario Europeo (SME), por lo que se adoptó una política monetaria restrictiva. Descartada la devaluación del tipo de cambio, la vía que quedaba para aumentar la competitividad era el control de precios y la represión salarial. La consecuencia era que el crecimiento no podía exceder ya de unos niveles compatibles con la estabilidad en la cotización de la peseta, que se había fijado en un nivel muy por encima del que habría sido el de equilibrio. 
A pesar de que la orientación productiva de la economía española cambió durante estos años, no puede decirse que hubiera un cambio en su especialización productiva. «La estructura industrial española de mediados de los años ochenta no se halla especializada en ramas en las que no lo estuviera ya una década antes» (Gómez, 1991, p. 481), al contrario que en otros países europeos, que afrontaron modificaciones de calado en sus sistemas productivos que les permitieron adaptarse a los cambios en la división internacional del trabajo. Cabe señalar que se profundizó la especialización siderúrgica y aumentó la participación de las ramas de transporte y química, muy internacionalizadas y de consumo creciente. En sentido contrario, tuvo lugar una desespecialización en maquinaria, equipos de oficina y material eléctrico.

Los cambios que se observan en la estructura industrial sancionan unos desequilibrios anteriores del sistema productivo, de manera que la economía española mantiene una especialización que se orienta hacia un conjunto de ramas de demanda menos progresiva, exentas de una capacidad transmisora de potencialidades de desarrollo desde el sector de bienes de producción. Se accede a un lugar «intermedio» en la división internacional del trabajo, en donde ciertas producciones estratégicas no tienen cabida en el sistema productivo interior y, por lo tanto, se abandonan al aprovisionamiento del comercio internacional. (Gómez, 1991, p. 486)

\section{PAPEL DEL ESTADO Y RECONVERSIÓN INDUSTRIAL}

En este apartado se trata de exponer la forma que toman, para el caso español, los cambios en el papel del Estado en la acumulación y de qué manera esta se ve afectada por su intervención. En un contexto de internacionalización en el que las economías nacionales son sometidas a la inestabilidad propia de un mercado mundial cambiante en continua expansión, se refuerza el papel de los Estados en lo concerniente al mantenimiento de los equilibrios fundamentales que den certeza sobre la reproducción del sistema en su conjunto.

Durante el crecimiento económico de posguerra, los Estados europeos dispusieron una serie de reglamentaciones para ordenar la actuación de los capitales nacionales al tiempo que acometieron inversiones y gestionaron aquellos bienes de los que el capital privado no estaba en condiciones de encargarse pero que eran indispensables para el funcionamiento de la economía capitalista. Desplegaron una serie de actividades encaminadas a procurar una demanda solvente y una fuerza de trabajo que cumpliera los requerimientos empresariales. Conforme avanza la internacionalización van perdiendo vigencia estos mecanismos y se revelan como rémoras para el desarrollo de las condiciones de acumulación en un marco de creciente competencia entre las burguesías nacionales. Esta competencia, espoleada por la tendencia secular a la concentración y centralización de los capitales a la que se une el progresivo agotamiento de los mercados nacionales por la saturación de mercancías, y ante la ausencia de reguladores institucionales a nivel mundial, solo encuentra límite en el marco institucional estatal. Opera así el arbitraje regulador de los capitales transnacionales, que buscan un espacio para valorizarse en unas condiciones lo más favorables que les sea posible. Sobre estas condiciones incide de forma más o menos directa la intervención y reglamentación del Estado, en especial por lo que se refiere a los efectos redistributivos que promueve en su función de regulador de la demanda y de disipador del conflicto social. 
En efecto, con la expansión del sector público y de su acción redistributiva se altera la distribución del ingreso entre salarios y rentas de la propiedad, se deprime el tipo de beneficio y se acaba reduciendo el espacio relativo del sector privado de la economía. (González, 1991b, p. 181)

En suma:

La adaptación de la producción industrial a las nuevas exigencias de la competencia exterior desdibuja y reorienta el carácter regulador de los Estados capitalistas. [...] La planificación y las políticas de corte nacional son abandonadas en el transcurso de la crisis, y la nueva industrialización supone la adaptación de las estructuras internas a las condiciones necesarias para atraer capitales extranjeros. (Gómez, 1991, p. 467)

En este sentido, la «expansión autónoma» del sector público termina por revelarse como disfuncional a las necesidades de la acumulación (González, 1991b). Así, en la medida en que la ley del valor opera a nivel mundial con cada vez menos restricciones, la función económica del Estado se va centrando en la transmisión y concreción de la disciplina de los mercados.

Podemos dividir nuestro periodo en cuatro fases de acuerdo al objetivo para cuya consecución se orienta la intervención del Estado. En la primera, que abarcaría hasta 1979, destacan las medidas asistenciales y redistributivas, como denota la abrupta subida de los gastos sociales y las transferencias, en un intento de suavizar el conflicto distributivo latente entre el capital y el mundo del trabajo. En una segunda etapa, hasta 1982, el crecimiento del gasto social obedece a razones de inercia, pues se empiezan a tomar medidas para limitarlo. A partir de 1983 la actuación estatal se encamina a la implantación del ajuste y la socialización de los costes de la crisis. Finalmente, desde 1987, relajado modestamente el conflicto distributivo, mejorada la situación de las cuentas públicas como consecuencia de la expansión económica que se había iniciado dos años antes y una vez cumplido el objetivo de la entrada en la CEE, se retoman ciertas políticas de inversión pública, principalmente en infraestructuras, y se elevan algunas prestaciones sociales (González, 1991b).

En España la crisis no impactó con todo su rigor hasta 1975 debido a las políticas públicas que promovieron grandes ampliaciones de capacidad en los sectores siderúrgico, metalúrgico y naval - que se hallaban en plena recesión- y a otras medidas de estímulo que propiciaron un elevado crecimiento artificial hasta 1974. La reacción al súbito encarecimiento de los precios del petróleo fue la contraria a la del resto de Estados: subsidios a la compra de petróleo y sus derivados. Esta política compensatoria se mantuvo hasta 1976, lo que se vino a sumar al pronunciado crecimiento del déficit y, sobre todo, impidió que se implementaran medidas de eficiencia energética. Hasta después de las elecciones de junio de 1977 no se produjo ningún tipo de ajuste ante la crisis, sino que se actuaba tratando de paliar sus consecuencias, bien mediante la nacionalización de empresas con pérdidas, que luego supondrían hasta un tercio de las pérdidas de todas las empresas públicas, bien mediante subvenciones a fondo perdido u otras medidas ad hoc encaminadas a la defensa de intereses sectoriales. También tiene lugar una expansión del sector público, con la aprobación de una nueva ley de financiación de la Seguridad Social en 1973 que aumenta las prestaciones, y la generalización del seguro de desempleo al año siguiente. En 1976, Villar Mir promovió una devaluación para ayudar a deshacerse de los excedentes siderúrgicos y, desde finales de año, de cara a las elecciones de 1977 se 
renunció a la aplicación de políticas fiscales y monetarias restrictivas. Esto causó un pequeño repunte en el crecimiento, pero alimentó las tensiones inflacionarias y el déficit exterior. En resumen, ante la falta de instrumentos adecuados y de apoyo social, unido a la debilidad política de los gobiernos de Arias Navarro y el primero de Suárez, se sacrificó en el corto plazo el ajuste, y con ello los equilibrios macroeconómicos y parte de los beneficios, en pos de paz social en un momento de efervescencia en la movilización obrera (González, 1991a).

La incapacidad de acometer ningún tipo de ajuste probablemente contribuyó a reforzar las malas expectativas empresariales y a agravar la mencionada huelga de inversiones. El escenario político cambió con el gobierno de Unión de Centro Democrático surgido de las elecciones de 1977, de las que emergieron interlocutores representativos y tras las que Suárez intentó, fructíferamente, implicar a todas las fuerzas sociales en una responsabilidad compartida ante el ajuste que había de producirse. Todas ellas compartían el modelo europeo basado en la «economía social de mercado», así como el diagnóstico y el tratamiento sobre la crisis:

Todos reconocían los desequilibrios macroeconómicos —inflación y déficit externo-, y los desajustes estructurales —energético, sectores en crisis—; del mismo modo, se reconocían las insuficiencias y desequilibrios institucionales: sector público, sistema fiscal, seguridad social, sistema financiero, relaciones laborales. De ahí que se admitiera la necesidad de un programa estabilizador, seguido de ajustes estructurales y reformas diversas. De nuevo, las diferencias aquí son de grado y no de fondo [...], lo único que se discute es el reparto del coste de la crisis. (González, 1991a, pp. 145-146)

Las negociaciones culminaron con rapidez en la firma por todos los partidos con representación parlamentaria de los Pactos de la Moncloa de 1977, en los que, por una parte, se acordaban las líneas de política económica y, por otra, el reparto del coste del ajuste. Según González, se trató, desde el punto de vista de la clase trabajadora, de:

[...] Un macrointercambio de democracia parlamentaria más un mínimo Estado asistencial por la asunción de parte del coste de la crisis. Lo que nadie podía adelantar entonces es que, en las posteriores «renovaciones» del acuerdo, los asalariados acabarían asumiendo la totalidad de la crisis, presionados por las urgencias de los desequilibrios internos y externos de nuestra economía y por el cambio en la correlación de fuerzas entre el capital y el trabajo, tanto en España como a nivel mundial. (González, 1991a, p. 146)

El ajuste tomó la forma de un clásico programa de austeridad excepto por el aumento de las prestaciones sociales: devaluación de la peseta, reforma fiscal restrictiva que aumentó la recaudación y la progresividad del sistema, política monetaria restrictiva y limitación salarial, al pasar la subida de salarios a calcularse en función de la inflación esperada, siempre menor a la efectiva. La estabilización surtió efecto y brindó oxígeno al Gobierno, que no llegó a desarrollar las reformas acordadas en los pactos, que por otra parte no preveían un control de su seguimiento y consistían en directrices sin mayores detalles. Ante la proximidad de las elecciones de 1979, el Gobierno aprobó algunas medidas expansivas y trató de rentabilizar políticamente la mejoría coyuntural tras la estabilización y el contexto internacional favorable, lo que llevó a la ruptura del consenso político. Sin embargo, a los pocos meses llegó el segundo shock del petróleo. 
El Gobierno, débil tras la ruptura del consenso y los malos resultados electorales 1979, careciendo de estrategia, solo pone en marcha medidas consistentes en parches y ayudas para restaurar el excedente empresarial a corto plazo, sin actuar sobre la situación de creciente obsolescencia del tejido productivo. Las transferencias a familias y empresas trasladan el conflicto distributivo al presupuesto público, mientras que la inversión pública alcanza sus niveles más bajos del periodo. Por su parte, continúa la política de rentas, al mantenerse los límites a la revalorización de los salarios, y se realiza una contrarreforma fiscal de carácter regresivo. Sobre el marco de relaciones laborales, en 1979 no se produce ningún acuerdo y entre 1980 y 1981 rige el Acuerdo-Marco Interconfederal, que incluye cláusulas de descuelgue y flexibiliza las condiciones laborales, lo que se plasmaría en el Estatuto de los Trabajadores. En general se tiende a reducir la capacidad de negociación de los trabajadores. La Ley Básica de Empleo limita las prestaciones por desempleo, mientras que en el Acuerdo Nacional sobre Empleo de 1981, posterior al intento de golpe de Estado del 23-F, se pacta por primera vez una reducción de los salarios reales. Por su parte, se enfrenta la crisis del sector financiero por las presiones de la banca y el deterioro económico, ya que las numerosas quiebras de empresas agravaban la situación de vulnerabilidad de los bancos. Entre 1978 y 1985, la mayoría de los bancos creados en los sesenta caerían en bancarrota. El resultado de esta reforma es el comienzo de la liberalización y el refuerzo del oligopolio en el sector. También se pone en marcha un programa de inversión en centrales nucleares basado en una importante sobreestimación de la demanda futura de energía en un 50\%; en 1983 se decretó la suspensión del plan, con un coste multimillonario que recaería sobre consumidores y contribuyentes. El déficit público pasa del 1,6\% al 5,6\% del PIB de 1979 a 1982, financiado mediante su monetización, reforzando la subida de la inflación, y mediante la emisión a tipos altos de deuda pública desgravable, beneficiando así las rentas de la propiedad.

El gobierno formado tras las elecciones de finales de 1982, en las que el Partido Socialista Obrero Español obtuvo 202 de los 350 diputados, contaba con la legitimidad suficiente como para abordar todos los ajustes y reformas que no se habían podido realizar hasta entonces. Políticamente, el Gobierno encara una solución de continuidad con los Pactos de la Moncloa, pero la situación de la economía en los últimos cinco años no había hecho sino agravarse, pues el desfase de la estructura productiva seguía aumentando. Las medidas que se implementaron fueron tanto de carácter coyuntural — nuevo ajuste macroeconómico con estabilización y saneamiento - como estructural — sentando las bases para restaurar la acumulación asegurando la recuperación del beneficio, mediante actuaciones que profundizaban en la desregulación y la liberalización-. Su coste fue socializado a través de la bajada de salarios reales y políticas monetarias y fiscales restrictivas. Como resultado, la participación de los salarios en el PIB cayó desde el 53,2\% en 1982 al 49,7\% en 1985. Así pues, «la acción del sector público español en la década de los 80 se enmarca a la perfección dentro de la estrategia global de política económica del periodo, en la que los objetivos asistenciales y de legitimación derivados de la transición política se han visto desplazados por las necesidades de acumulación del capital y los costes de la crisis» (González, 1991b, p. 189).

En el Plan Económico a Medio Plazo de 1979 se reconoció por primera vez la necesidad de una reconversión industrial, que ya se plantea con un enfoque sectorial. Durante los meses siguientes se fueron publicando decretos concernientes a diversos sectores como el naval, la 
siderurgia integral, electrodomésticos, aceros especiales, textil o auxiliar del automóvil, entre otros, pero hasta 1981 no se publicó la Ley de Reconversión, que contaba con muchas insuficiencias. Mientras tanto, se continuó con la nacionalización de empresas con pérdidas a través del Instituto Nacional de Industria y la concesión de créditos y avales. En resumen, las acciones que se pusieron en marcha estaban desarticuladas, no se enmarcaban en una estrategia con objetivos definidos y se realizaron sin contrapartidas a la ayuda pública recibida. Atendiendo las urgencias financieras en el corto plazo según la capacidad de presión de cada empresa, no se hizo nada por remediar los males estructurales que les afectaban (González, 1991a).

Los gobiernos a partir de 1982 variaron su actuación según las características del sector. Los más atomizados apenas recibieron recursos públicos, por lo que la ley del mercado se encargó de dejar solo las empresas más competitivas, con la consiguiente pérdida de empleos. Se trata de los casos del textil, el calzado o la madera. Por el contrario, en aquellos sectores más oligopolizados se actuaba transfiriendo recursos hacia las grandes empresas en detrimento de las públicas, en caso de haberlas, y de las pequeñas. Los casos más representativos son los sectores bancario y siderúrgico. En cuanto a los sectores que contaban con una fuerte presencia de multinacionales extranjeras, recibían ayudas compensatorias por afrenta comparativa, como en automóviles (González, 1991b). Entre 1978 y 1984, de la pérdida de empleos en la industria, casi la mitad correspondió a productos metálicos, madera y corcho y, especialmente, textil, vestido y calzado. A partir de la integración en la CEE se perdió la autonomía estatal para el saneamiento de ramas y de reconversión de grandes empresas (Gómez, 1991). Hasta entonces, no existían restricciones impuestas para la adhesión, pero ésta se argumentaba desde el Gobierno como imperativo de las ganancias de competitividad que había que acometer a pesar de los sacrificios de empleo.

Por lo que respecta a la empresa pública, el sector se introdujo en un proceso de descapitalización. Las condiciones de ajuste de estas empresas fueron sustancialmente más duras que para las privadas, lo que se tradujo en una importante conflictividad laboral. El objetivo que se perseguía para la empresa pública no era otro que el de la rentabilidad, que, cuando se lograba, se transmitía al capital privado mediante su privatización. En este proceso de saneamiento y posterior venta de activos se empleó una cantidad ingente de recursos públicos (González, 1991b).

Una administración que intervenía en la asignación privada de recursos - con normativas, coeficientes obligatorios, etc. - se ha tornado en otra que asigna activa y directamente sus propios recursos, obtenidos por el sistema fiscal, el endeudamiento o la venta de patrimonio público y que, además, crea a costa propia espacios y oportunidades económicas al sector privado (González, 1991b, p. 233).

\section{CONCLUSIONES}

En este artículo se ha contextualizado la crisis que atravesó la economía española durante aproximadamente una década desde la segunda mitad de los años setenta. Por una parte, con atención a la situación socioeconómica del país durante ese tiempo y, por otra, en relación a los cambios que simultáneamente se estaban produciendo en el plano internacional. El enfoque analítico de la ley del valor permite dilucidar las constricciones a que se enfrentan los capitalistas para sobrevivir en unos mercados cada vez más desarrollados y competitivos. También, 
por tanto, el Estado, en tanto garante último de la reproducción del sistema en una economía mundial donde la ley del valor opera a escala mundial con cada vez menos obstáculos. En el marco del proceso de internacionalización de los mercados, el modo de intervención estatal en la economía cambia sustancialmente.

Según lo expuesto, puede predicarse la excepcionalidad del conocido como «milagro español», fenómeno incomprensible aislado de los factores que lo posibilitaron; a saber, una situación inicial de subdesarrollo y pauperización y una etapa de altos y sostenidos niveles de inversión en la industria. Estos mismos factores tienen un importante poder explicativo acerca de la especial severidad de la crisis. De un lado, la industrialización de la economía española no fue lo suficientemente intensa en capital como para acercarse al nivel de productividad de las industrias europeas más desarrolladas, en buena medida debido a los bajísimos costes laborales que desincentivaban una mayor mecanización. De otro, cuando la clase trabajadora contó con fuerza para imponer subidas de los salarios reales por encima de la productividad y de los precios, la extracción de plusvalía y la capacidad de muchos capitalistas para seguir compitiendo se resintieron.

Por lo que respecta a las hipótesis anunciadas, se ha encontrado base para confirmar las tres. Si bien para contrastar de forma estricta la presencia de un salario máximo habría que realizar una serie de mediciones y comprobación de más datos de que no se dispone, las aportaciones de diversos autores sugieren que durante los gobiernos de Adolfo Suárez los salarios alcanzaron unos niveles incompatibles con el mantenimiento de la acumulación, al menos en la forma concreta en que se daba en la economía española en este tiempo. No parece haber lugar a dudas sobre la hipótesis de que hubo momentos de impasse en la intervención pública tendente a restaurar la tasa de ganancia y que la tardanza en practicar el ajuste sobre las bases de la acumulación no hizo sino agravar el problema que en algún momento habría de abordarse. Solo con la alteración de la correlación de fuerzas en la disputa capital-trabajo, desfavorable para este último, contemporánea a la llegada de un gobierno fuerte con un amplio respaldo de la clase trabajadora y sus organizaciones, se pudo aplicar la desvalorización de la fuerza de trabajo que demandaba el curso de la acumulación capitalista en España. En cuanto a la última hipótesis, se encuentra una continuidad inequívoca en la motivación que impulsa el diseño de la política económica, cual es la atención a los intereses más inmediatos de los grandes capitales. Para el caso concreto español se trataba especialmente de capitales con cercanía al poder político que operaban en mercados muy oligopolizados y cuya actividad genera pocas innovaciones productivas con efectos de arrastre sobre el resto del tejido productivo. La actuación estatal en la economía consistió en una serie de parches en forma de transferencias públicas al sector privado y, con el tiempo, en una política de devaluación salarial como manera de competir en los mercados internacionales. Careció, por tanto, de toda planificación estratégica orientada incidir en una determinada especialización exterior de la economía o en mayores ganancias de productividad en la industria. En este sentido, la reconversión industrial se limitó a socializar el coste de las numerosas quiebras y favorecer el proceso de centralización del capital.

De lo estudiado aquí se desprenden posibles líneas de investigación que abundarían en un mejor conocimiento acerca de qué es contingente y qué es necesario en la forma que toma la acumulación en España. Sería preciso analizar el papel que desempeña la economía española 
en la división internacional del trabajo tratando de determinar la influencia que ejercen el diseño y la disciplina de las instituciones de la Unión Europea sobre las posibilidades de intervención del Estado en la economía.

Cabe ampliar el periodo de estudio hasta los últimos años para comprobar cómo el esquema crisis-ajuste-crisis se ha desarrollado desde entonces con una agudización del conflicto y la competencia en cada episodio. Merecería la pena estudiar qué ramas o sectores productivos obtienen mayor rentabilidad y por qué. En definitiva, se trataría de comprender qué hay detrás del hecho de que la acumulación en España se desarrolle con los capitalistas renunciando a explotar a masas de trabajadores en tal grado como en ninguna otra economía, lo que se traduce en el fenómeno crónico del desempleo.

\section{REFERENCIAS}

Albarracín, J. (1991). La extracción del excedente y el proceso de acumulación. En M. Etxezarreta (Coord.), La reestructuración del capitalismo en España, 1970-1990. Barcelona, España: FUHEM.

Arrizabalo, X. (2014). Capitalismo y economía mundial. Madrid, España: Instituto Marxista de Economía. Astarita, R. (2006). Valor, mercado mundial y globalización. Buenos Aires, Argentina: Ediciones Kraikon. Braña, F. J. (1981). La función económica del Estado capitalista. Contribución al análisis del proceso de industrialización dependiente en España, 1964-1977. Madrid, España: Universidad Complutense de Madrid.

Cámara, S. (2005). The dynamics of the profit rate in Spain (1954-2001). Review of Radical Political Economics (39), 543-561.

Cardoso, F. y Faletto, E. (1969). Dependencia y desarrollo en América Latina. Buenos Aires, Argentina: Siglo Xxi Editores.

Catalán, J. (1991). Del «milagro» a la crisis: la herencia económica del franquismo. En M. Etxezarreta (Coord.), La reestructuración del capitalismo en España, 1970-199o. Barcelona, España: FUHEM.

Echebarria, G., y Herrero, J. L. (1989). La evolución de la economía española durante el periodo 1940-1988 a partir de un indicador de la tasa de beneficio del sector industrial. Economía española (665), 9-24.

Gómez, M. (1991). La internacionalización de la industria española: un proceso acelerado. En M. Etxezarreta (Coord.), La reestructuración del capitalismo en España, 1970-199o. Barcelona, España: FUHEM.

González, J. (1991a). Crisis, transición y estancamiento. La política española, 1973-1982. En M. Etxezarreta (Coord.), La reestructuración del capitalismo en España, 1970-199o. Barcelona, España: FUHEM.

González, J. (1991b). Transformación del sector público e intervención en la economía. En M. Etxezarreta (Coord.), La reestructuración del capitalismo en España, 1970-1990. Barcelona, España: FUHEM.

Marx, K. (2009 [1894]). El capital. Crítica de la economía política. Libro tercero. El proceso global de producción capitalista. México DF, México: Siglo xxI.

Montes, P. (1991). La integración en la Comunidad Económica Europea en el marco de la internacionalización del capitalismo español. En M. Etxezarreta (Coord.), La reestructuración del capitalismo en España, 1970-199o. Barcelona, España: FUHEM.

Navinés, F. (1989). Crisis económica y política económica. El caso de la economía española (1964-1986). Economía española (665), 25-44. 